\title{
Rehearsal of professional practice: impacts of web-based collaborative learning on the future encounter of different disciplines
}

\author{
Ahmet Fatih Karakaya · Burcu Şenyapılı
}

Received: 17 April 2006/ Accepted: 27 September 2006/ Published online: 29 December 2006

(C) Springer Science+Business Media B.V. 2006

\begin{abstract}
This study argues that the shift towards a more multidisciplinary professional life in contemporary design practice requires design curricula to equip students with collaborative skills. The study offers that by the aid of web-based collaborative learning (WBCL) in design education, different disciplines may be brought together during their education. A case study is held as a rehearsal of professional life; involving architecture and interior architecture students collaborating on a common project, using WBCL. The evaluations of the participating students about the process were analyzed. The findings convey that there is a mutual problem of recognition of professional domains. In order to diagnose and possibly reconcile tensions that may occur due to this problem in professional life, this paper asserts that integrating interdisciplinary work to the design curricula would be beneficial.
\end{abstract}

Keywords Architecture - Design communication · Interdisciplinary collaboration · Interior architecture $\cdot$ Web-based collaborative learning

\section{Introduction}

In today's professional world, collaboration between different disciplines is becoming inevitable due to the broadening scope of the tasks done. With this rapid shift to multidisciplinary tasks in practice, higher education needs to adjust itself to equip future practitioners with collaborative skills. The focus of the design curricula on the individual needs to readjust itself acknowledging the teamwork outside in the market (McCormick, 2004). With the developments in information and communication technologies (ICT) students are provided with a wide range of possibilities to collaborate, causing some changes in the educational system as well (Ragoonaden \&

A. F. Karakaya $(\bowtie) \cdot$ B. Şenyapılı Interior Architecture and Environmental Design, Bilkent University, Faculty of Art, Design and Architecture, Ankara 06800, Turkey

e-mail: afatih@bilkent.edu.tr 
Bordeleau, 2000). Especially current web-based tools create more flexible conditions for collaborative learning in terms of time and place both for students and instructors (Cox, Carr, \& Hall, 2004). Students can easily collaborate synchronously and asynchronously via web-based tools.

In design education, web-based tools are becoming widely used (Craig \& Zimring 2000; Rummel, Spada, Hermann, Caspar, \& Schornstein, 2005), especially in the form of online design studios. Broadfoot and Bennett (2001) define online design studio as a web-based studio, which is a "networked studio, distributed across space and time'; such that the participants of an online design studio maybe in different locations handling design communications via computers. In other words, participants of an online design studio are 'collaborating'.

Considering that design is an entirely interactive process; where the designer constantly interacts especially with her/himself in pursuing a satisfactory design solution, it may be asserted that in collaborative design, this interaction is increased and diversified; each group consults with the instructor(s) and other groups throughout the collaborative process. Besides the efforts of the instructor(s), collaborating with fellow students, and developing a project together contributes positively to the process. Most online design studios encourage students to share, discuss and develop design ideas together, as teams. This process is open-ended while it maintains a focus on the overall goal. Usually collaborators develop a very strong ownership for the process and respond very positively to the fact that they are given almost complete responsibility to deal with the problem posed to them (Panitz, 2005).

Collaborative works make design students consider the needs, skills and design solutions from different perspectives. Collaborative design emerges from the process; working together in a manner to enhance each participant's contribution to the design solution (Achten, 2002). In collaborative actions, individuals are responsible for their actions, and they respect the abilities and contributions of their peers (Panitz, 2005). Group members share authority and accept responsibility for the group actions. The main concept of collaborative learning is the consensus through cooperation by group members, in contrast to competition.

For design education the impact of web-based collaborative learning (WBCL) on the learning process, on the quality and quantity of design solutions, and on the design process in general are hot debates in academia. Especially, while students are mostly exposed to technologies that support individual disciplines, the use of collaborative information tools is comparatively rare (Soibelman, O'Brien, \& Evlin, 2003). Within this framework, this paper locates itself within these discussions and offers a perspective to examine how WBCL can be utilized in order to rehearse the market encounter of different disciplines, reconciling possible tensions while enhancing the strongest aspects.

\section{How can WBCL be used for the encounter of two different disciplines during their education?}

As WBCL encourages cooperation rather than competition between the group members, it is intriguing whether web-based collaboration applications during education would aid in establishing an effective collaboration in professional practice between two different, yet closely related disciplines, ostensibly competing at times, rather than cooperating. Architecture and interior architecture, being two 
disciplines that contemplate each other, the necessity of collaboration is evident in professional life. However, due to working in the same greater domain, the task distribution may sometimes become problematic, as each profession may claim to be responsible for the same task. Here, the crucial question to be asked is whether current design curricula are presenting architecture and interior architecture students with the necessary tools and abilities that prepare them for the needs and difficulties of future collaboration in practice?

It is common for interior architects having to collaborate with other professionals such as architects, civil engineers, and mechanical engineers in practice. However, throughout interior architecture education, students usually do not have many chances to collaborate with members of these or other disciplines; they often work on their projects individually (IIDA Report, 1998). As such, they are not encouraged to improve communication skills with other disciplines. When these students graduate, soon they are confronted with the collaborative reality of today's professional practice, and they may often end up feeling inadequate in terms of collaboration skills.

From the perspective of architectural education, similarly, students mostly work on projects individually and often they are not specifically encouraged to improve their collaborative skills (Howes, 2003). However unlike interior architects, due to the broad scope of their education, it is often the case that when architecture students graduate, they feel that they are in charge of all design duties, comprising interior finishing, details, decisions.

No doubt, the overlapping of tasks aids in the formation of problems related to job and responsibility distribution. In professional life, architects may fail to recognize a separate domain of tasks for interior architects, while interior architects may be deprived of their autonomy trying to fit in the same field with the architects (Hildebrant, 2004; IIDA report, 1998; Thompson \& Guerin, 2002). This is largely due to the overlapping of professional domains in areas like space planning, space programming, space layout, selection of materials, furnishings and components. This overlapping may become so evident that in some cases, the responsibilities of an architect and an interior architect may conflict with each other, creating a battle for professional duties.

Kienle's (2006) argument about the diverse development of educational and professional tools is valid for the web-based tolls in design curricula, and design profession.

To date the development of technical systems to support learning either in schools and universities (CSCL-systems), or in companies (knowledgemanagement systems) have largely developed separately concurrent, with no or little mutual exchange of experience. (p. 161)

This paper asserts that the contradictory position taken by the professions may be overcome to an extent by enhancing design curricula with collaborative experiences. Interior architects and architects should be confronted with each other in their educational life, so that they would be prepared for the future encounter in professional life. As such, they may learn, discuss, and get mutually familiar with each other's terminologies, ways of doing, and approaches. Rummel et al. (2005) refer to interdisciplinary collaboration as "complementary exercise", where designers from different disciplines have to cope with working together for solving the design problems at hand. As the central idea behind the design studio may be described by Schön's concept of 'learning by doing' (1987), such a complementary exercise may be considered as learning how to cope with the professional life by actually collaborating. 
Within this context, a study is executed in order to examine whether a sample encounter would aid in terms of recognition of mutual domains, experiencing teamwork, and being exposed to one another's terminology and discipline. The aim is to make almost a rehearsal of the professional life, observing and assessing students' reactions. Chang, Sung, \& Lee (2003) pointed to the aspect of modern education involving students' active participation in learning through exploratory actions. Extending these actions, this study suggests that students should explore ways and means of collaborative communication while actively participating in a professional encounter.

\section{Methodology}

The focus of the study was a web-based collaborative experience involving both architecture and interior architecture students. McCormick (2004) draws attention to the use of ICT in a setting where the camps are remotely positioned.

In as much as teachers in schools see themselves as reflecting the world of design and technology outside, then first they need to encourage collaborative design for their students. Second, ICT as a tool in design is increasingly a collaborative tool and teachers will need to help students to use it in this context. Such collaboration will not just be as a convenience (because there are insufficient computers) or as a group collaborating around a single computer, but also as remote collaboration, where students are physically separated. (p. 162)

In our case, a total of 37 students, geographically separated, participated in the study, collaborating on a joint project over a web-based platform. After the study was completed, the contentment and evaluation of the students were analyzed through a set of questionnaires.

Case study

Two elective courses were selected, one from Delft Technical University (TUDelft), Netherlands and one from Bilkent University, Turkey. Both universities currently administer curricula that are reinforced by digital applications. The TUDelft course BK 6810 Audio Visual Production course had 21 architecture students, and the Bilkent course IAED 316 Computer Application course had 16 interior architecture students who participated in this case study (Fig. 1).

Students formed groups consisting of interior architecture and architecture students, and each group designed 'a Turkish Store in the Netherlands' collaboratively. Groups were generally composed of 2 interior architecture students and 3 architecture students. There were 8 groups in total. In order to facilitate the collaboration on the World Wide Web, a platform (InfoBase) developed by the TUDelft, was utilized. InfoBase enabled the information collected and generated by the students to be stored, exchanged, and manipulated. Collaboration between the two universities took about 9 weeks. As the most effective collaboration occurs at early design stages (Wilson \& Harris, 2003), during the 9 weeks' period students were encouraged to collaborate densely for the first half. In other words, after a dense collaborative process for 5 weeks, Bilkent students took over the project and developed the project further for 4 more weeks for the final presentation. 
Fig. 1 Formulation of collaborating teams

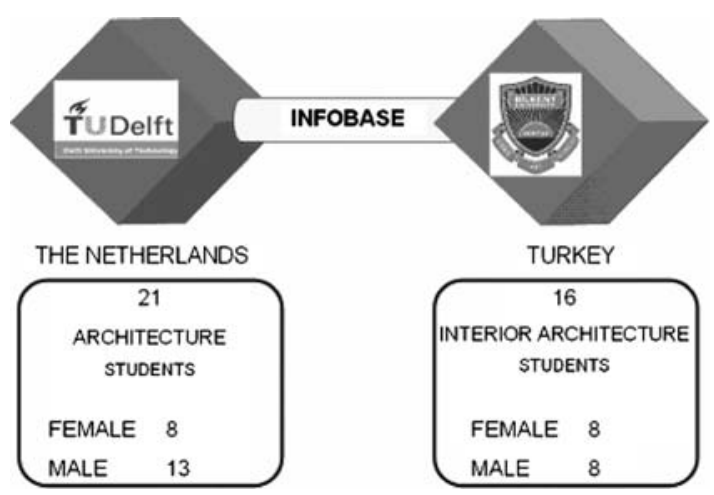

The architecture students uploaded the envelope structure of the building, inside, which the store would be located. Interior architecture students downloaded the building in .dxf (drawing interchange format) and used software like AutoCAD and/ or 3DS Max to develop, share and communicate their designs. During the collaboration, architecture students were responsible for establishing a client profile, presenting the context of the built environment and the facade, and giving architectural decisions. Interior architecture students, on the other hand, were responsible for arranging the interior elements (such as partition walls, stairs, allocation of spaces, etc.), designing the lighting, acoustics, furniture and establishing a circulation pattern.

\section{Findings}

After the completion of the study, held jointly involving interior architecture and architecture students, participating students were asked to fill a questionnaire. This questionnaire was composed of several parts:

- Questions to assess the demographic characteristics and computer usage;

- Internet backgrounds;

- Questions related to the perception of the other discipline;

- Evaluation of collaboration with the other discipline.

\section{Demographics}

Overall mean age of the participating students was 22.5 for the group, consisting of 21 male and 16 female students. All participating students had previous computer experience, the least one being 4 years and the maximum one being 17 years. Again, all students had previous Internet experience, the least one being 3 years and the maximum 11 years. Regarding Internet use, the mean for interior architecture students was 5.8 years $\left(m_{\mathrm{ia}}=5.8\right)$, and the mean for architecture students 6.8 years $\left(m_{\mathrm{a}}=6.8\right)$. In general, both student groups had computer experience that led them to feel confident in using computers. With minor differences, both student groups indicated that they were skilled in dealing with computers (Table 1). 
Table 1 Evaluation of self-confidence in computer use

\begin{tabular}{lll}
\hline Student confidence/experience & Arch. stud. & Int. arch. stud. \\
\hline Confidence in using the WWW & 6.8 & 5.8 \\
Confidence in using the search engines & 6.6 & 6.5 \\
Confidence in using e-learning platforms & 5.4 & 5.6 \\
Confidence in using messenger services & 6.1 & 6.3 \\
I experience virtual way-finding by trial-error & 5.3 & 6.1 \\
Getting frustrated while dealing with computers & 3.1 & 2.8 \\
Others seem more skilful & 3.9 & 3.7 \\
I feel isolated & 3.5 & 4.5 \\
\hline
\end{tabular}

Working with the other discipline

Both interior architecture and architecture students seemed to have benefited from working with the others. On a 5 point scale their assessments were as follows:

- Working with the members of another discipline made both student camps learn more $\left(m_{\mathrm{ia}}=3.9, m_{\mathrm{a}}=3.0\right)$.

- Both disciplines were excited working with the other $\left(m_{\mathrm{ia}}=4.9, m_{\mathrm{a}}=3.9\right)$.

Although, both camps declared mutual excitement and gain, there were divergences as well:

- Interior architecture students indicated working with architecture students led to a more successful design $\left(m_{\mathrm{ia}}=4.4\right)$, whereas architecture students were uncertain $\left(m_{\mathrm{a}}=2.8\right)$.

- Interior architecture students agreed that working with architecture students developed their projects in a manner that otherwise they would hardly imagine $\left(m_{\mathrm{ia}}=3.5\right)$. Again architecture students were uncertain about the positive impact of collaboration on the development of their projects $\left(m_{\mathrm{a}}=2.4\right)$.

- Working with architecture students made interior architecture students recognize the domain of architecture $\left(m_{\mathrm{ia}}=4.3\right)$ as an entity other than their own. However, architecture students indicated that interior architecture is part of their task domain, not necessitating collaboration with another discipline $\left(m_{\mathrm{a}}=2.7\right)$.

- Interior architecture students felt more confident as professionals while working with architecture students $\left(m_{\mathrm{ia}}=4.7\right)$. Architecture students declared to have lesser confidence while working with interior architecture students $\left(m_{\mathrm{a}}=3.8\right)$.

- Interior architecture students agreed that working with architects contributed to the formulation of design solutions $\left(m_{\mathrm{ia}}=4.1\right)$. Yet, architecture students were uncertain about contribution of interior architects to the formulation of design solutions $\left(m_{\mathrm{a}}=2.7\right)$ (Table 2$)$.

\section{Collaboration}

A four-part set of questions were asked in order to determine the students' overall evaluation of the collaborative process:

- Yes/no questions

- Evaluation of collaboration

Springer 
Table 2 Evaluation of working with other discipline

\begin{tabular}{lll}
\hline Student satisfaction & Arch. stud. & Int. arch. stud. \\
\hline Made me learn more & 3.0 & 3.9 \\
Made me excited & 3.9 & 4.9 \\
Led to a more successful design & 2.8 & 4.4 \\
Developed the project in ways I hardly could imagine & 2.4 & 3.5 \\
Made me recognize the domain of other discipline & 2.7 & 4.3 \\
Made me feel confident & 3.8 & 4.7 \\
Contributed to the formulation of design solutions & 2.7 & 4.1 \\
\hline
\end{tabular}

- Open-ended questions

- Pre-determined problems

\section{a. Yes/no questions}

First, a set of yes-no questions with open-ended extensions was introduced to determine students' overall evaluation of the idea of collaboration with another discipline:

- Both groups felt that they were clearly expressing themselves to the other discipline.

- Both groups expressed that they would willingly collaborate with the other discipline in the future.

- Both disciplines agreed that collaboration with other discipline is necessary in their education.

- Both camps also agreed that collaboration with other discipline is necessary in their professional life (Table 3).

\section{b. Evaluation of collaboration}

Secondly, students were asked to evaluate collaboration with another discipline in terms of easiness, flexibility, quickness, provision of information, clarity of design submissions, and fun, grading each item on a 5 to 1 scale:

- In terms of easiness, most architecture students stated that collaboration with interior architecture students was difficult (Table 4), whereas interior architecture students were more focused around the middle of the scale.

Table 3 Evaluation of collaboration with other discipline

\begin{tabular}{llc}
\hline Student satisfaction & Arch. stud. & Int. arch. stud. \\
\hline Clearly expressing yourself to other discipline & 4.45 & 4.28 \\
Willingly collaborate w/ other discipline in the future & 4.15 & 4.00 \\
Collaboration w/ other discipline is necessary in education & 4.35 & 4.05 \\
Collaboration w/ other discipline is necessary in professional life & 3.80 & 3.65 \\
\hline
\end{tabular}


Table 4 Collaboration with other discipline was difficult-easy

\begin{tabular}{lll}
\hline Number of students & Arch. stud. & Int. arch. stud. \\
\hline 1 (Difficult) & 8 & 2 \\
2 & 1 & 2 \\
3 & 2 & 6 \\
4 & 0 & 3 \\
5 (Easy) & 0 & 2 \\
\hline
\end{tabular}

Table 5 Communication with other discipline was limiting-

\begin{tabular}{lll}
\hline Number of students & Arch. stud. & Int. arch. stud. \\
\hline 1 (Limiting) & 4 & 2 \\
2 & 3 & 2 \\
3 & 2 & 6 \\
4 & 2 & 2 \\
5 (Free) & 1 & 2 \\
\hline
\end{tabular}

- As for flexibility, architecture students' evaluated the communication as limiting, more than interior architecture students did (Table 5).

- In terms of provision of information, architecture students found design submissions mostly uninformative while interior architecture students rated design submissions of architecture students as informative (Table 6).

- As for the clarity of design submissions, according to architecture students, the design submissions that they received were confusing, however, interior architecture students indicated that architecture students sent them clear design data (Table 7).

- In terms of fun, according to interior architecture students, collaboration with architecture students was fun. Architecture students seemed to have enjoyed the collaboration as much (Table 8).

\section{c. Open-ended questions}

Thirdly, a set of open-ended questions asked the students the strongest and the weakest points in collaborating with the other discipline. Interior architecture

Table 6 Design submissions of other discipline were informative-uninformative

Table 7 Design submissions of other discipline were confusing-clear

\begin{tabular}{lll}
\hline Number of students & Arch. stud. & Int. arch. stud. \\
\hline 1 (Uninformative) & 6 & 1 \\
2 & 4 & 0 \\
3 & 1 & 4 \\
4 & 0 & 5 \\
5 (Informative) & 0 & 5 \\
\hline
\end{tabular}

\begin{tabular}{lll}
\hline Number of students & Arch. stud. & Int. arch. stud. \\
\hline 1 (Confusing) & 5 & 1 \\
2 & 1 & 0 \\
3 & 5 & 7 \\
4 & 0 & 3 \\
5 (Clear) & 0 & 4 \\
\hline
\end{tabular}


Table 8 Collaboration with other discipline was boring-fun

\begin{tabular}{lll}
\hline Number of students & Arch. stud. & Int. arch. stud. \\
\hline 1 (Boring) & 2 & 0 \\
2 & 3 & 3 \\
3 & 3 & 3 \\
4 & 1 & 3 \\
5 (Fun) & 2 & 6 \\
\hline
\end{tabular}

students referred to the "richness of views" as the strongest aspect, and as the weakest aspect they pointed out to the "unconsciousness of architecture students about what interior architects were responsible of". Similarly, architecture students also referred to the "richness of ideas" as the strongest aspect of collaboration; however, they stated the opinion that "they would have achieved a successful design without the contribution of the interior architecture students".

\section{d. Pre-determined problems}

Finally, a table comprising pre-determined problems that could affect the collaboration was given with a 1 to 5 scale of frequency, where students would indicate the occurrence of a problem between 1 as 'never' to 5 as 'always'. The types of problems were stated as: incompatibility of vocabularies, difference in working discipline, approach to design problems, incompatibility of design tools, dominance of the other discipline, inequality of task distribution, quality of design submissions, informative content of the design submissions, and trust in professional competence (Fig. 2). The joint results pointed out to the inequality of task distribution with the highest mean in parallel to the initial assumptions of this paper.

\section{Discussions}

Chiu (2002) describes the collaborative design studio by name, location, work relationships, human contacts, and data communication. Following his description our work may be identified as in Table 9.

\section{Gender}

Gender distribution was balanced on interior architecture students' side by 8 males and 8 females, however, architecture students group was more male dominated with 13 males and 8 females. The study groups comprised of mixed genders where both were given the same opportunities.

\section{a. Demographics}

A previous study found out a significant gender difference in computer attitudes among interior architecture undergraduates of Bilkent students with males having 


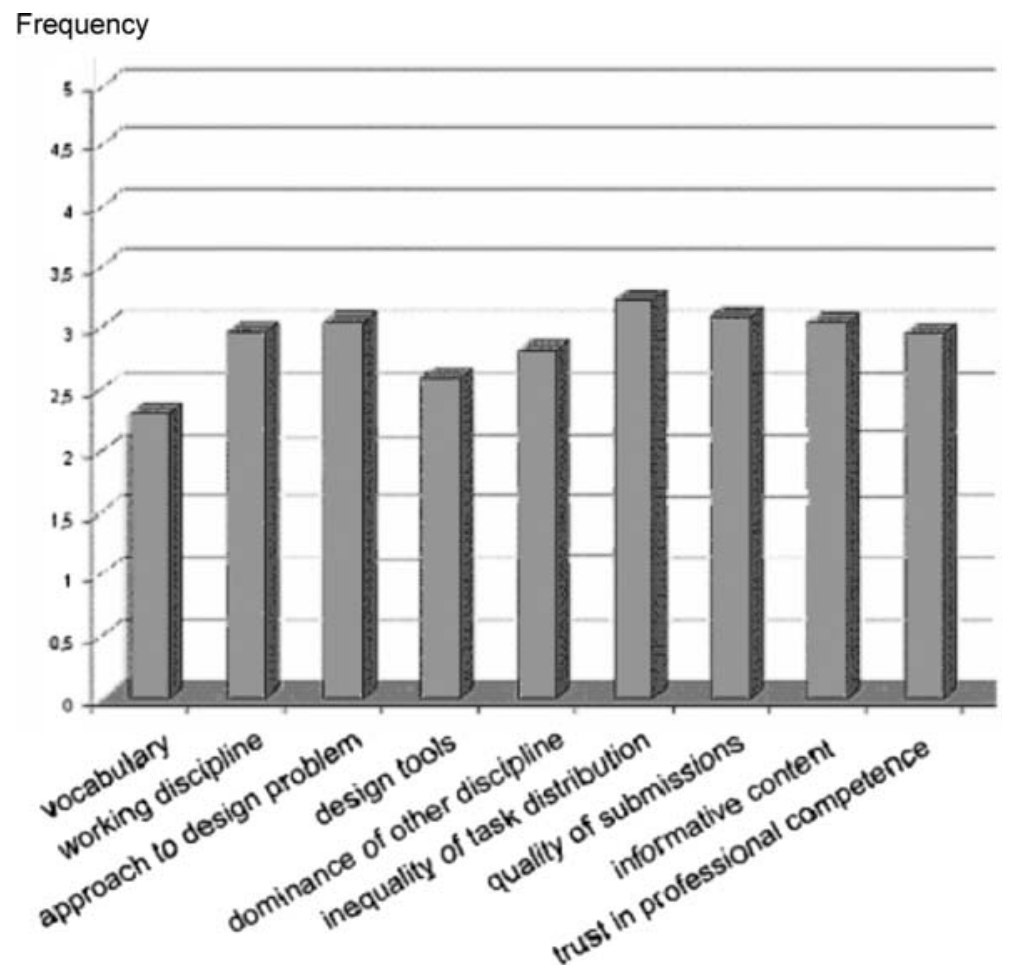

Fig. 2 Problems in the encounter of the two disciplines

more positive attitudes than females (Pektaş \& Erkip, 2006). In our study, which covered both Bilkent and TUDelft students, similarly, male students were more experienced in computer and Internet use, feeling more skilled using computers, thus, having more tendency for trial and error method of using computers. However, being more experienced and feeling more comfortable in using computers did not lead to a significant difference in male students' satisfaction/dissatisfaction with the collaborative work.

Table 9 Description of collaborative work following Chiu's (2002) model

\begin{tabular}{|c|c|c|c|c|}
\hline Name & Location & Work relations & Human contacts & Data communication \\
\hline $\begin{array}{l}\text { Turkish } \\
\text { Store } \\
\text { in the } \\
\text { Netherlands }\end{array}$ & $\begin{array}{l}8 \text { groups } \\
\text { from } 2 \\
\text { institutions } \\
\text { at } 2 \text { cities } \\
\text { (Delft and } \\
\text { Ankara) }\end{array}$ & $\begin{array}{l}\text { All groups } \\
\text { jointly design } \\
\text { in a parallel } \\
\text { process }\end{array}$ & $\begin{array}{l}\text { (1) Weblog } \\
\text { (2) E-mail } \\
\text { (3) Telephone } \\
\text { (4) MSN } \\
\text { Messenger } \\
\text { (5) Face-to-face } \\
\text { contact among } \\
\text { certain group } \\
\text { members and } \\
\text { related instructors }\end{array}$ & $\begin{array}{l}\text { (1) The same CAD } \\
\text { system (AutoCAD) } \\
\text { (2) Exchange of files } \\
\text { through InfoBase }\end{array}$ \\
\hline
\end{tabular}




\section{b. Working with the other discipline}

There were no significant differences in the evaluation of working with the other discipline between male and female students. The issue that the male students were the most positive (mean difference $=0.8$ ) compared to the females was the other discipline's contribution to the formulation of design solutions $\left(m_{\text {male }}=3,8\right.$; $m_{\text {female }}=3,0$ ). The issue about which female students were slightly (mean difference $=0.3$ ) more positive was working with the other discipline helped in realizing the other discipline's domain $\left(m_{\mathrm{m}}=3,4 ; m_{\mathrm{f}}=3,7\right)$.

\section{c. Collaboration}

In general male and female students had similar ideas on the process of collaboration. The most significant result where male students differed from the females was the location of collaboration on a linear easy/difficult scale. Male students found collaboration easier compared to females. Female students differed from male students in indicating the difference in working discipline as a problem in collaboration $\left(m_{\mathrm{m}}=2,9 ; m_{\mathrm{f}}=3,9\right)$.

\section{Ramifications of the case study}

The case study engaged both architecture and interior architecture students as active participants in collaborating in and evaluating a technology-mediated learning environment. It may not be disregarded that the students' overall satisfaction may be influenced by the following factors, which are carefully considered and organized through prior meetings to make minimum impact.

\section{a. Performance of the exchange platform}

The exchanged platform (InfoBase) used in this study is developed by TUDelft and it is being used by Dutch students since 2002. Akar, Tunçer, Stouffs, \& Attema, (2003) evaluated InfoBase in terms of its usability, usefulness and experience of users about their group work. The results of a similar collaborative work held between TUDelft and a partner university showed that InfoBase proved to be a viable E-learning environment. The results particularly indicated that when the number of users is big, the motivation increases as well. Therefore, in our study we merged two groups.

\section{b. Language}

Although, the native languages are different, the design curricula of both universities are held in English. The students participated in our study from both universities had at least two years of prior design education in English, enabling them to have a proper communication in English. As both parties did not use their native language and both communicated in English, language wise communication conditions were balanced. 


\section{c. Culture}

The cultural dimension of the study introduced two different cultures (Turkish and Dutch). Interior architecture students being from Turkey and architecture students being from the Netherlands led to the formation of the groups where always two cultures would be present. However, these two particular cultures are not totally foreign to each other. The fact that Turkish immigrant workers chose The Netherlands as one of the major destinations in the labour wave in the second half of the 20th century initiated merging of the two cultures. Even three of the architecture students from TUDelft have indicated their nationality as being both Dutch and Turkish.

In a previous study, design students from Hong Kong, Zurich and Seattle have collaborated on a special project in which the three cultures were deliberately reflected onto the client and site profiles (Kolarevic, 1999). Similarly, the project chosen for our collaborative work was consciously established to accommodate both cultural contexts by building a 'Turkish' store in a 'Dutch' setting.

\section{d. Turkish versus Dutch instruction}

The design curricula of both schools are aligned with the international design principles aiming to equip students with adequate skills to execute designs all over the world. For other differences that might arise due to calendars, schedules, work and course loads, credits, etc. representatives from both universities paid mutual visits in order to discuss and eliminate problems. The faculty, in other words, collaborated as well.

\section{e. Negative outcomes}

While the above factors may have still affected the overall satisfaction with the collaborative study, they are not directly related to the emergence of the discomforts arising in the encounter of the disciplines. Indeed, the findings illustrate the difficulty of interior architects in being recognized as members of an autonomous discipline by the architects. Pollard, Devon, McKay, \& Bilén, (2002) found similar results in a joint international collaboration between groups from two engineering curricula. Students indicated cultural differences, differing criteria and design processes used at two universities as negative factors. However, their overall perception of collaboration was positive; they found the collaboration interesting, useful and wanted to repeat the experience. In line with this, the findings further enhance the validity of our initial argument that the two disciplines need to and may benefit from encountering during education, and a web-based platform proves to be a relevant and usable tool for this encounter. However, we observed some negative aspects.

- Given the facilities of both universities students had to share computers. Each group share one computer, sitting in front of one monitor side by side, one person from the group being in charge of communication. This is what McCormick (2004) indicates as a problem in collaborative group participation. Ideally, students should have interconnected monitors and keyboards for each member of the group. 
- In the general schedule of the collaborative work several videoconferencing sessions were planned. Unfortunately, they could not be realized. This was partly due to technical problems as well as budget related ones. We believe that if realized, videoconferencing would have helped in enhancing group communication (Bender, 2005; Kolarevic, Schmitt, Hirshberg, Kurmann, \& Johnson, 1998).

- Time constraints have at times projected a negative dimension on the collaborative work, leading to discontentment of the students. However, considering the time constraints students will be confronted with as professionals in real life collaboration, we believe that the time related constraints to be off experiential value.

McCormick (2004) states two themes within collaborative works as 'collaborating to learn' and 'learning to collaborate'. According to McCormick, participation in technological activity is collaborative. Hence, learning to participate, and/or learning to collaborate becomes as a natural consequence. In our case, students dealt with a design project collaborating with each other for the purpose of learning. The results of working with the other discipline indicate that their impression was that they learned more compared to regular studio work. As for learning to collaborate, McCormick classifies experience in the sequence of: deciding steps in process, resolving difficulties, and decision taking. We observed that all these three steps were experienced by the students who participated in our study.

Simoff and Maher (2000) demonstrated how the communication records can be used to analyse participation and contribution in a collaborative project. In our case, students were forwarded to a special destination in Weblog and/or to Microsoft MSN Messenger for both synchronous and asynchronous discussions. A thorough analysis of the discussions in the Weblog and the MSN Messenger revealed that especially in the step of resolving difficulties (McCormick, 2004) these free discussion platforms helped a lot. The communication in these media also pointed out to several issues:

- In the discussions students repetitively referred to the time conflicts and problems in synchronous meeting; "we are waiting for you.......... come here please... need to communicate.." (Weblog)

- Discussions often evolved around disciplinal and collaborative inconsistencies in work share; "As we are interior architecture students; we hope your comments as you are architecture students." (Weblog)

- Despite the extensively planned capacity of InfoBase and high capacity of connection speed provided by both universities especially during the last stages of the project transfer of large file sizes sometimes caused transmission failures.

- Weblog/MSN communications also showed that some individual problems stemming from the character(s) of group members might have been misinterpreted as disciplinal and/or collaborative problems by the students.

Encounter of the two disciplines

Brinkerhoff and Koroghlanian (2005) stated that students with prior Internet-based experience are more positive towards Internet-based instruction. The demographics of the two participating groups of our study had prior experience in computer and Internet use, therefore indicating a presumed positive attitude towards a 
computer-mediated instruction and collaboration. The acquaintance and experience of this particular level of the TUDelft students is high because they need to complete prior prerequisite computer courses (Akar et al., 2003). In previous studies, conducted with the same level of Bilkent University students, it was also found out that they had high computer and Internet experience (Şenyapılı and Karakaya, 2005). In another study, Bilkent interior architecture students' general attitude toward computer use was found positive (Pektaş \& Erkip, 2006). As such, we tend to blame much of the discontentment on the encounter of the disciplines rather than on a discomfort in using technology.

Although recent studies draw attention to the indisposition between interior architecture and architecture (Havenhand, 2004; Hildebrant, 2004; Thompson \& Guerin, 2002) there are no studies that directly aim at reconciling the tensions between the two disciplines. Studies in the field of WBCL bring together different disciplines and proved to be beneficial in terms of merging of the disciplines (Romice \& Uzzell, 2005) yet, few studies (Franklin \& Sessoms, 2005) have been conducted to enable the encounter of complimentary disciplines in the virtual environment, and in the field of design (Bender, 2005; Chen et al., 2004).

No doubt, communication is fundamental to collaboration (Jones \& Kasif, 1997). For a proper communication initially the communicating sides should have reciprocal acknowledgment. The findings pointed out supporting clues to the initial argument of this paper that architecture students had a tendency to see themselves as capable of doing all design tasks; almost only enjoying working alone. Persistence of such perceptions may lead to conflicting situations in professional life. Encountering with interior architects during the course of education may aid in rehearsing the future collaborations by demonstrating the possible communication problems and hopefully some solutions. Kvan (2000) argues that collaboration involves and it essentially should involve compromising. Such a collaborative experience should equip the students with compromising skills.

In this study, architectural students, although not satisfied totally with the interior architect's design submissions' quality, still acknowledged that the interior architects are able to contribute positively to the design process. Moreover, both camps realized that their vocabularies and design criteria were similar, stating that working with the other discipline in educational and professional life is necessary.

\section{Educational benefits}

This study was an effort to introduce teamwork of different disciplines in education. According to Howes (2003),

There is movement towards teamwork in the construction industry. This is less obvious in education. (p. 6)

The students were expected to compliment each other in order to reach a common goal. Each student was not a novice in the other's domain and at the same time was not an expert in his own. It was previously asserted that both architecture and interior architecture curricula mostly encourage students to put forth individual design abilities, leading them to be more comfortable working individually. Consequently, these two disciplines have a rather problematic encounter in the market. According to Blossom, Matthews, \& Gibson (2002), if students are introduced with 
the values and scope of work of the other discipline during education possible misconceptions could be eliminated before students adopt stereotypical behaviours. Within this framework, the encounter of design students during their education turned out to be an asset. The similarities and dissimilarities of the disciplines provided a rich setting for exploring cross-disciplinal collaboration and an understanding of interdisciplinary spatial processes. In addition, the collaborative experience provided an opportunity for critical reflections on the discipline-space relationship, helping to define task distribution better.

The collaboration had a number of educational benefits for the students in general; they:

- Gained an appreciation of the other discipline, in terms of its tasks and design approach

- Had the opportunity to develop and share richer ideas;

- Experienced that the discipline differences, and differences in opinions and beliefs are central to collaborative projects of this kind;

- Rehearsed how to establish and handle inter-disciplinary communication, using professional terminology;

- Experienced the difficulties and benefits of managing task distribution.

In particular, working with students of another discipline made the students recognize 'the other domain' and perceive the overlapping of boundaries between two disciplines. This study was almost a 'role playing', and it gave the students the notion of the challenging conditions of today's interdisciplinary professional practice.

\section{Conclusion}

The evaluation of this web-based collaborative design studio practice points out to the potential of virtual design studios where students of different disciplines and geographies establish, develop, share design ideas and rehearse for professional encounters of the market. In these new virtual design studios, there are rich opportunities for building innovative and effective communities for design education in which the traditional boundaries of time, culture, language, discipline, and institution are blurred and new configurations for design learning become possible. Moreover, the explicit and tacit knowledge, as grouped by Triggs and John (2004), needing to be combined in order to educate the 'enabled professional';

One who has the capacity to respond to changing conditions, anticipate future technologies and re-define their practice so that they are enabled rather than constrained by external policy agendas", may become integrated into design education. (p. 427)

In conclusion, developments in information and communication technologies and multidisciplinary design world need to be integrated in design curricula. Designrelated disciplines need to collaborate during their education for a proper preparation for the contemporary design world. Web-based tools provide a suitable base for this collaboration. The interdisciplinary tensions that may occur during the collaboration should be closely monitored and solutions geared towards the elimination of these tensions need to be integrated into the design curricula. Future 
research should not be limited but needs to include a broader perspective in terms of reflections on gender difference in the encounter of disciplines, implications of disciplinal tensions on the development of interdisciplinary collaborative tools and technology, and assessment of market performances of students who have experienced interdisciplinary collaborative work in their education.

\section{References}

Achten, H. H. (2002). Requirements for collaborative design in architecture. In H. Timmermans (Ed). Sixth design and decision support systems in architecture and urban planning-part one: Architecture proceedings (pp. 1-13). Avegoor, The Netherlands

Akar, E., Tunçer, B., Stouffs, R., \& Attema, J. (2003). 'Design and evaluation of a collaborative virtual space', in 9th EIA Conference Proceedings (pp. 3-12) İstanbul, Turkey

Bender, D. M. (2005). 'Developing a collaborative multidisciplinary online design course', The Journal of Educators Online, 2(2), Retrieved from http://www.thejeo.com/Diane\%20Bender\%20Final.pdf

Blossom, Matthews \& Gibson (2002). cited in Bender, D. M. (2005). 'Developing a Collaborative Multidisciplinary Online Design Course', The Journal of Educators Online, 2(2), Available from http://www.thejeo.com/Diane\%20Bender\%20Final.pdf

Brinkerhoff, J., \& Koroghlanian, C. M. (2005). Student computer skills and attitudes toward internet-delivered instruction: An assessment of stability over time and place. Journal of Educational Computing Research, 32(1), 27-56

Broadfoot, O., \& Bennett, R. (2001). 'Design Studios: Online? Comparing traditional face-to-face design studio education with modern internet-based design studios', Retrieved from http:// www.omnium.edu.au/assets/downloads/list/omnium_paper_rb_ob_2003_auc.pdf

Chang, K. E., Sung, Y. T., \& Lee, C. L. (2003). Web-based collaborative inquiry learning. Journal of Computer Assisted Learning, 19(1), 56-69.

Chen, P. L., Cui, L., Wan, C., Yang, Q., Ting, S. K., \& Tiong, R. L. K. (2004). Implementation of IFC-based web server for collaborative building design between architects and structural engineers. Automation in Construction, 14(1), 115-128.

Chiu, M. L. (2002). An organizational view of design communication in design collaboration. Design Studies, 23(2), 187-210.

Cox, G., Carr, T., \& Hall, M. (2004). Evaluating the use of synchronous communication in two blended courses. Journal of Computer Assisted Learning, 20(3), 183-193.

Craig, D. L., \& Zimring, C. (2000). Supporting collaborative design groups as design communities. Design Studies 21(2), 187-204.

Franklin, C. A., \& Sessoms, D. B. (2005). A situative perspective on a collaborative model for integrating technology into teaching. Journal of Educational Computing Research, 32(4), 315328.

Havenhand, L. K. (2004). A view from the margin: Interior design. Design Issues, 20(4), 32-42.

Hildebrant, H. (2004). 'The gaps between interior design and architecture'. Design Intelligence, 10(3), Retrieved from http://www.di.net/article.php?article_id $=308$

Howes, J. (2003). 'Working Together', in CIB W89 International Conference on Building Education and Research (BEAR 2003) (Vol. 3, 1390-1405). Salford, UK, Retrieved from http:// www.cebe.heacademy.ac.uk/learning/sig/teamworking/pdf/Jaki\%20Howes\%20-\%20Leeds\%20Met.pdf

IIDA Report: (1998). A study of interior design: Analysis of the need of practice and implications for education. International Interior Design Association. Retrieved from http://www.iida.org/files/ pdf_found_education_analysis.pdf

Jones, P. \& Kasif, S. (1997). Breakout Group 2: Communication and Collaboration. Paper presented at the NSF Workshop on Human-Centered Systems: Information, Interactivity, and Intelligence (HCS), Arlington, VA. Retrieved from http://www.ifp.uiuc.edu/nsfhcs/bog_reports/bog2.html

Kienle, A. (2006). Integration of knowledge management and collaborative learning by technical supported communication processes. Education and Information Technologies, 11(2), 161-185.

Kolarevic, B. (1999). 'Virtual design studio: Computing, telecommunications, and architectural design'. In J. James (Ed.), Quality in teaching and learning in higher education: A collection of 
refereed papers from the first conference on quality in teaching and learning in higher education (pp. 200-205). The Hong Kong Polytechnic University, Educational Development Centre

Kolarevic, B., Schmitt, G., Hirshberg, U., Kurmann, D., \& Johnson, B. (1998). 'Virtual design studio: Multiplying time', in ECAADE'98 Conference

Kvan, T. (2000). Collaborative design: What is it? Automation in Construction, 9(4), 409-415.

McCormick, R. (2004). Collaboration: The challenge of ICT. International Journal of Technology and Design Education, 14(2), 159-176.

Panitz, T. (2005). 'Collaborative versus cooperative learning - A comparison of the two concepts which will help us understand the underlying nature of interactive learning', Retrieved from http://home.capecod.net/ tpanitz/tedsarticles/coopdefinition.htm

Pektaş, Ş. T., \& Erkip, F. (2006). Attitudes of design students toward computer usage in design. International Journal of Technology and Design Education, 16(1), 79-95.

Pollard, J. D., Devon, R. F., McKay, A., \& Bilén, S. G. (2002). Teaching design through international collaboration. Manchester England: International Conference for Engineering Education (ICEE).

Ragoonaden, K. \& Bordeleau, P. (2000). Collaborative Learning via the Internet. Educational Technology \& Society, 3(3), 1-16.

Romice, O. \& Uzzell, D. (2005). Community design studio: A collaboration of architects and psychologists. CEBE Transactions, 2(1), 73-88.

Rummel, N., Spada, H., Hermann, F., Caspar, F., \& Schornstein, K. (2005). 'Promoting the coordination of computer-mediated interdisciplinary collaboration: Vicarious learning from workedout examples and the effects of different technical settings', Retrieved from http://newmedia.colorado.edu/cscl/26.pdf

Schön, D. A. (1987). Educating the reflective practitioner. San Francisco: Jossey-Bass.

Şenyapilı, B., \& Karakaya, A. F. (2005). Design studio communication: Young generation holding on to old techniques. In Innovation in Architecture, Engineering and Construction (pp. 375-385). Rotterdam: Optima Grafische Communicatie.

Simoff, S. J., \& Maher, M. L. (2000). Analysing participation in collaborative design environments. Design Studies, 21(2), 119-144.

Soibelman, L., O’Brien, W., \& Evlin, G. (2003). Collaborative design processes: A class on concurrent collaboration in multidisciplinary design. Journal of Construction Education, 8(2), 78-93.

Thompson, C. A., \& Guerin, D. A. (2002). The challange: Transformation of interior design education and practice'. Retrieved from http://www.designmatters.net/whitepaper/Tatum $\% 20$ Award.pdf

Triggs, P., \& John, P. (2004). From transaction to transformation: Information and communication technology, professional development and the formation of communities of practice. Journal of Computer Assisted Learning, 20(6), 426-439.

Weblog. Retrieved from http://turkishstore.blogspot.com/

Wilson, V., \& Harris, M. (2003). Designing the best: A review of effective teaching and learning of design and technology. International Journal of Technology and Design Education, 13(3), 223-241. 